\title{
MONITORING SUHU KABEL TRAFO MELALUI TAMPILAN LCD DAN SMS
}

\author{
Umi Fadlilah, Nina Saniya \\ Jurusan Teknik Elektro, Fakultas Teknik Universitas Muhammadiyah Surakarta \\ Surakarta, Indonesia \\ umi.fadlilah@ums.ac.id, nina.sania23@gmail.com
}

\begin{abstract}
Abstrak - Salah satu bagian sistem tenaga listrik yang penting tapi kurang diperhatikan perawatannya adalah transformator, terutama pada bagian kabel transformator/trafo. Di Indonesia, pengecekan suhu kabel trafo masih dilakukan secara manual dan tidak terusmenerus, sehing ga diperlukan alat yang dapat memantau secara continue dan realtime. Pemonitor suhu ini dapat mengetahui suhu kabel trafo di tiap fasanya, misalnya pada Gardu Induk PLN (Pembangkit Listrik Negara). Sensor suhu yang digunakan adalah DHT22. Hasil pembacaan sensor diproses oleh arduino UNO R3, sehingga tampil di LCD (Liquid Crystal Display), selanjutya dikirim dengan SMS (Short Message Service) menggunakan modul SIM800L ke smartphone. Jika suhu kabel trafo kurang dari $40.00^{\circ} \mathrm{C}$, maka trafo dalam keadaan normal dan indikator LED hijau menyala. Jika suhu melebihi nilai tersebut, maka indikator LED merah dan buzzer menyala. Pada keadaan berlebih arduino akan mengirimkan pesan yang berisi informasi suhu tiap fasanya ke petugas. Walaupun tidak sedang di lapangan untuk memonitor, namun petugas dapat mengetahui suhu berlebih dan segera melakukan tindakan. Hasil monitoring suhu akan ditampilkan pada LCD 16x2 dan selanjutnya ditampilkan ke smartphone berupa pesan teks.
\end{abstract}

Kata Kunci-Arduino UNO R3, DHT22, modul SIM800L, SMS, suhu, smartphone.

\section{PENDAHULUAN}

Transformator adalah salah satu bagian penting dalam suatu sistem tenaga listrik yang berfungsi untuk mengonversi daya tanpa mengubah frekuensi listrik. Namun, transformator biasanya menjadi peralatan listrik yang kurang diperhatikan dan tidak diberikan perawatan yang memadai. Pengecekan suhu pada trafo pun dilakukan secara manual oleh petugas yang tidak memungkinkan berjaga 24 jam, sedangkan lonjakan beban dapat terjadi kapan saja yang akan menyebabkan suhu pada kabel trafo meningkat. Penggunaan perangkat monitoring dan sensor suhu akan membuat pengecekan suhu dapat optimal secara continue dan real time.

Sensor yang digunakan untuk mendeteksi suhu itu bervariasi, salah satunya adalah DHT22 yang merupakan sensor pengukur suhu dan kelembaban relatif dengan output berupa sinyal digital dengan galat relatif pengukuran suhu 4\% dan kelembaban 18\% (Saptadi, 2014). Prinsip kerja dari DHT22 yaitu saat mendeteksi suhu dan kelembaban di sekitarnya, maka akan diketahui nilainya dari hasil pembacaan sensor. Sensor DHT22 mempunyai kelebihan dalam kecepatan pembacaan suhu, ketelitian, serta daya tahan yang baik. Contohnya ada alat yang dirancang menggunakan sensor DHT22 dan dilakukan percobaan dengan termometer digital, maka suhu yang terukur memiliki selisih 0.93, serta kelembaban yang terukur lebih cepat mengalami penyesuaian (Islam, 2016).

Pengukuran suhu dilakukan menggunakan DHT22 berbasis Arduino, dan ditampilkan menggunakan LCD $16 \times 2$ dan smartphone android untuk penampilan hasil SMSnya. Arduino merupakan platform terbuka yang dapat digunakan untuk mengembangkan 
interaktif objek, mengambil input dari berbagai switch atau sensor dan mengendalikan berbagai lampu, motor dan output lainnya (Kumar, 2013). Setelah diolah oleh arduino, hasil pengukuran suhu akan ditampilkan ke LCD. LCD adalah modul yang sangat dasar dan umum digunakan di berbagai perangkat dan rangkaian (Agarwal, 2016), yang berfungsi sebagai interface/antar muka untuk menampilkan hasil dari suatu pengukuran. Apabila suhu hasil pengukuran melebihi batas yang telah ditentukan, maka arduino akan mengirim pesan teks ke smartphone android melalui SMS menggunakan modul SIM800L berupa peringatan ke nomor petugas yang telah ditetapkan. Penggunaan sensor DHT22 telah dilakukan oleh Pasha, tahun 2016 dalam karyanya berjudul "Thingspeak Based Sensing and Monitoring System for IoT with Matlab Analysis" dengan memakai lima sensor yang berbeda untuk mengetahui panas, kelembaban, suhu, intensitas cahaya, sensor hujan, dan kualitas udara.

Short message service merupakan layanan dasar smartphone yang berfungsi untuk mengirim dan menerima pesan tertulis. Layanan ini masih banyak digunakan oleh para pengguna android, sehingga petugas akan mendapatkan informasi tentang nilai suhu pada kabel trafo di saat melebihi $40.00^{\circ} \mathrm{C}$ secara langsung serta tanpa adanya batas jarak antara petugas dan alat monitoring.

Pengiriman SMS berupa data atau hasil dari pembacaan sensor yang diproses oleh arduino ke petugas menggunakan modul SIM800L. Modul SIM800L adalah salah satu modul GSM/GPRS serial yang dapat digunakan bersama Arduino/AVR.

\section{PERANCANGAN}

\section{A. Metode}

\section{Perancangan sistem}

Perancangan sistem monitoring suhu kabel trafo ditunjukkan pada Gambar 1 menggunakan arduino UNO R3, saklar, DHT22 tiga buah untuk tiap fasa pada kabel trafo, LCD, android, indikator LED hijau dan merah, buzzer, modul SIM800L, stepdown untuk modul SIM, serta rangkaian power supply.

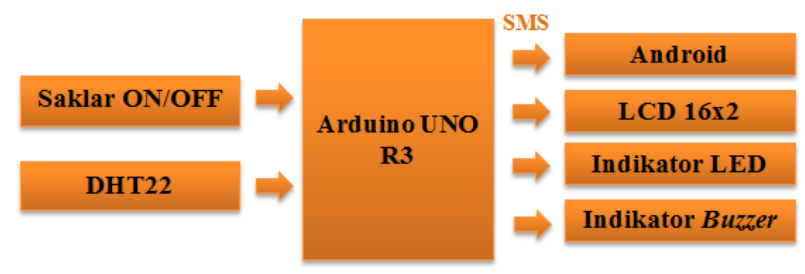

Gambar 1. Blok diagram alat monitoring suhu

Sensor DHT22 akan mengirimkan data suhu kabel trafo ke arduino. Arduino akan memproses nilai yang didapat dari sensor dan ditampilkan ke LCD. Apabila suhu kabel trafo di atas $40.00{ }^{0} \mathrm{C}$, maka arduino akan mengirimkan SMS menggunakan modul SIM800L serta buzzer dan LED merah akan menyala. Jika tidak dalam keadaan tersebut, maka LED hijau menyala, LED merah dan buzzer mati. Suhu yang didapat akan diketahui oleh petugas yang ada di lapangan dengan LCD maupun di luar lapangan dengan SMS yang berisi informasi suhu saat meningkat sehingga dapat segera dilakukan tindakan.

Tabel 1. Rekomendasi Thermovisi dari PLN

\begin{tabular}{|c|c|c|}
\hline $\mathbf{N}$ & $\Delta \mathbf{T}$ & Rekomendasi \\
\hline 1. & $<10^{0} \mathrm{C}$ & $\begin{array}{lr}\text { Kondisi } & \text { normal, } \\
\text { pengukuran } & \text { berikutnya } \\
\text { dilakukan sesuai jadwal }\end{array}$ \\
\hline 2. & $\begin{array}{l}10^{0} \mathrm{C}- \\
25^{0} \mathrm{C}\end{array}$ & $\begin{array}{l}\text { Perlu dilakukan } \\
\text { pengukuran } \\
\text { lagi }\end{array}$ \\
\hline 3. & $\begin{array}{l}25^{0} \mathrm{C}- \\
40{ }^{\circ} \mathrm{C}\end{array}$ & $\begin{array}{l}\text { Perlu direncanakan } \\
\text { perbaikan }\end{array}$ \\
\hline 4. & $\begin{array}{l}40^{\circ} \mathrm{C}- \\
70^{\circ} \mathrm{C}\end{array}$ & $\begin{array}{l}\text { Perlu dilakukan perbaikan } \\
\text { segera }\end{array}$ \\
\hline 5. & $>70^{\circ} \mathrm{C}$ & Kondisi darurat \\
\hline
\end{tabular}

Data pada Tabel 1 merupakan rekomendasi nilai suhu yang digunakan dalam penentuan derajat suhu kabel trafo. Jadi, dalam menentukan batas-batas nilai suhu kabel trafo 
didapatkan rangenya dan digunakan sebagai perintah yang akan diproses oleh arduino.

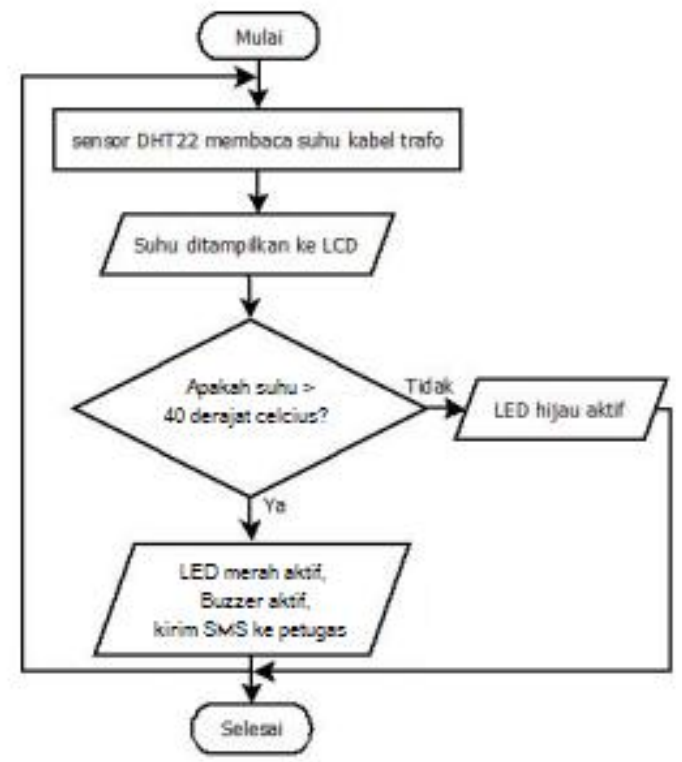

Gambar 1. Flowchart Alat Monitoring Suhu

Flowchart monitoring suhu kabel trafo pada Gambar 1 dimulai dari proses pembacaan suhu kabel trafo oleh sensor DHT22. Arduino akan memproses nilai suhu kabel trafo. Suhu yang terbaca akan ditampilkan ke LCD. Hasil pengukuran akan diinformasikan ke petugas jika melebihi $40.00^{\circ} \mathrm{C}$ melalui SMS sehingga mereka dapat segera menuju lapangan untuk melakukan tindakan perbaikan. Pada saat yang bersamaan, indikator LED merah dan buzzer akan menyala. Jika tidak dalam keadaan tersebut, maka indikator LED hijau saja yang menyala, setelah itu proses akan kembali berulang ke pengukuran suhu secara otomatis.

\section{B. Perancangan Hardware}

Perancangan hardware/perangkat keras monitoring suhu kabel trafo ini melibatkan semua komponen eleketronika yang dibutuhkan agar kerja sensor bisa optima. Desain/perancangan dibuat dengan memperhitungkan dimensi komponen yang digunakan yakni LCD, arduino, modul SIM800L, stepdown, saklar, dan power supply. Software coreldraw digunakan untuk merancang alat seperti Gambar 2.

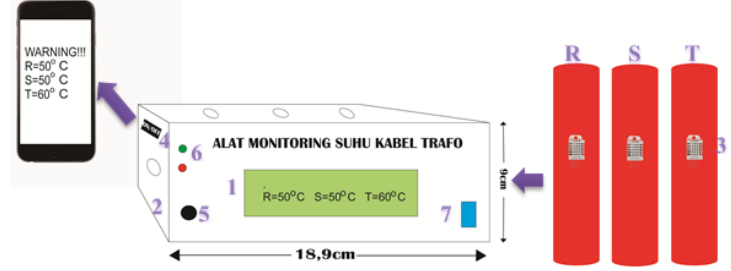

Gambar 2. Desain Rancangan Alat Monitoring Suhu Trafo

Keterangan dari Gambar 2:

1. Tempat LCD

2. Tempat arduino, power supply, modul SIM800L, stepdown

3. Sensor DHT22

4. Saklar ON/OFF

5. Buzzer

6. LED indikator

7. USB Arduino

\section{Perancangan Rangkaian Elektronika}

Rancangan rangkaian skematik alat menggunakan software proteus 7 yang ditunjukkan pada Gambar 3. Skematik ini digunakan untuk menentukan letak DHT22, saklar, indikator LED dan buzzer, modul SIM800L, stepdown serta LCD pada pin-pin arduino. Tegangan masukan juga ditentukan oleh skematik rangkaian ini. Transformator berfungsi untuk menurunkan tegangan sumber dari PLN 220 volt, dioda untuk menyearahkan, sedangkan IC7809 digunakan untuk meregulasi, kemudian dihasilkan tegangan 9 volt. Hasil tegangan inilah yang masuk ke arduino. Tegangan pada arduino sebesar 5 volt karena sudah terdapat regulator yang berfungsi untuk menurunkan sehingga pin pada arduino dapat digunakan oleh komponen lainnya.

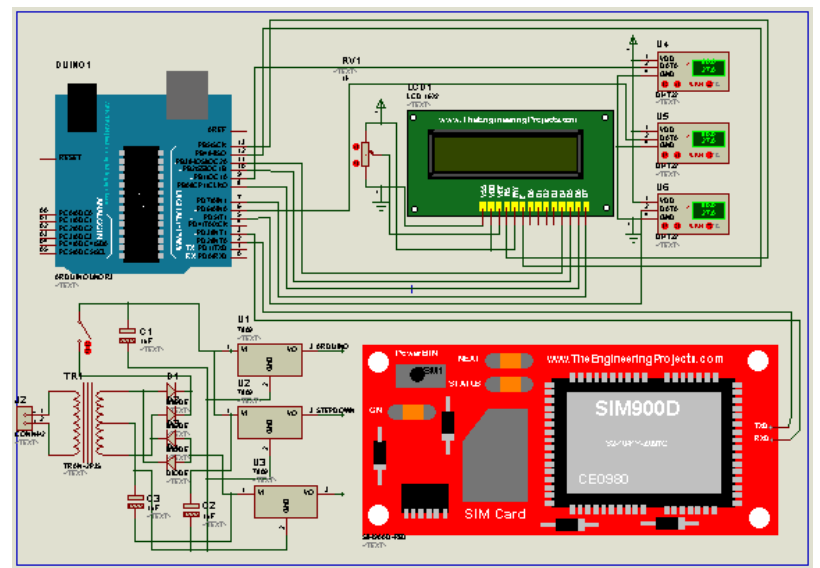

Gambar 3. Rangkaian Skematik 
Pembuatan rangkaian PCB dilakukan menggunakan software diptrace meliputi jalur saklar, power supply, dan sill arduino. Pembuatan ini bertujuan agar jalur PCB dan komponen yang satu dengan komponen lain yang digunakan tersusun rapi serta saat melakukan pengukuran suhu bisa aman serta mudah dalam menghubungkan komponenkomponen tersebut.

Bahasa pemrograman $\mathrm{C}++$ digunakan dalam pemrograman alat monitoring ini menggunakan arduino. Script pengambilan nilai suhu oleh DHT22 terdapat pada Gambar 4. Adapun Gambar 5 menunjukkan komunikasi SMS ke smartphone dari arduino.

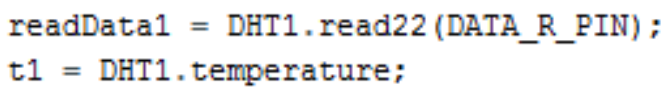

Gambar 4. Program Pengambilan Nilai Suhu

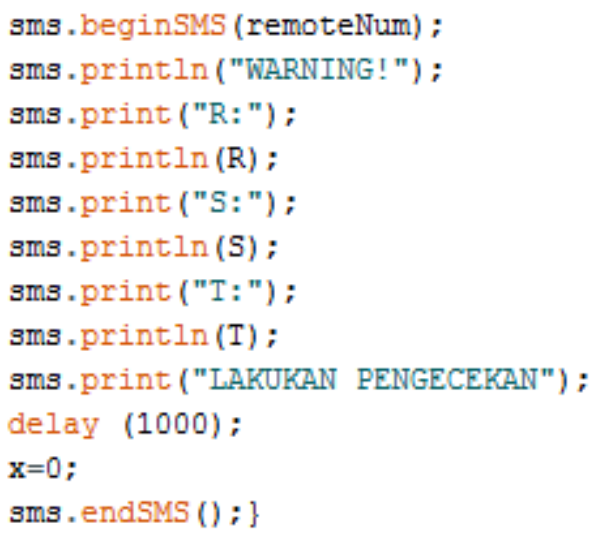

Gambar 5. Program komunikasi SMS

\section{HASIL DAN PEMBAHASAN}

Perancangan hardware dan software menghasilkan pemonitor suhu pada kabel trafo dengan 3 sensor DHT22.

\section{A. Hasil Perancangan Hardware}

Alat monitoring suhu ditunjukkan pada Gambar 6. Sensor DHT22 sebagai alat pendeteksi suhu ditunjukkan pada nomor 1 . LCD yang digunakan untuk display nilai pengukuran pada nomor 2. Kabel USB arduino untuk merubah program pada nomor 3. LED sebagai indikator suhu pada nomor 4. Buzer sebagai alarm pengingat suara pada nomor 5 , sedangkan saklar ON/OFF terdapat pada nomor 6 .

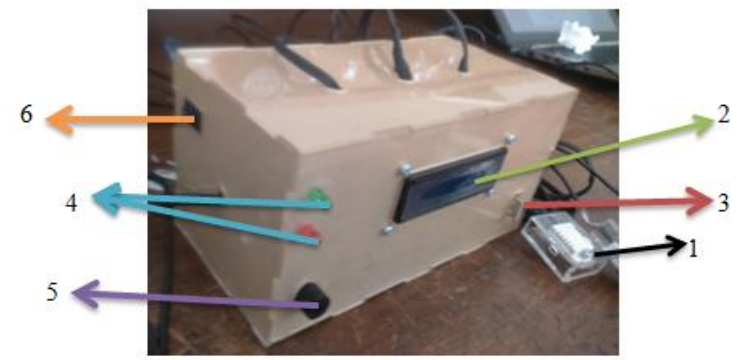

Gambar 6. Alat monitoring suhu

B. Hasil Pengujian DHT22

Tabel 2. Pengujian DHT22

\begin{tabular}{|c|c|c|c|c|c|c|c|}
\hline \multirow[b]{2}{*}{ No. } & \multicolumn{3}{|c|}{ Alat ukur suhu } & \multicolumn{3}{|c|}{ Indikator } & \multirow{2}{*}{$\begin{array}{c}\text { Delay } \\
\text { Tertam } \\
\text { pil } \\
\text { (detik) }\end{array}$} \\
\hline & $\mathbf{R}\left({ }^{\circ} \mathrm{C}\right)$ & $\mathbf{S}\left({ }^{\circ} \mathrm{C}\right)$ & $\mathbf{T}\left({ }^{0} \mathrm{C}\right)$ & $\begin{array}{c}\text { LED } \\
\text { Hijau }\end{array}$ & $\begin{array}{c}\text { LED } \\
\text { Merah }\end{array}$ & Buzzer & \\
\hline 1 & 25.70 & 28.80 & 34.90 & $\mathrm{ON}$ & OFF & OFF & 1 \\
\hline 2 & 25.70 & 36.80 & 28.80 & ON & OFF & OFF & 1 \\
\hline 3 & 38.20 & 34.20 & 31.20 & ON & OFF & OFF & 1 \\
\hline 4 & 33.50 & 36.70 & 40.00 & OFF & ON & ON & 1 \\
\hline 5 & 36.50 & 40.20 & 33.10 & OFF & ON & ON & 1 \\
\hline 6 & 40.00 & 38.90 & 35.20 & OFF & ON & ON & 1 \\
\hline 7 & 33.90 & 37.10 & 39.50 & ON & OFF & OFF & 0.5 \\
\hline 8 & 33.20 & 36.00 & 39.70 & ON & OFF & OFF & 0.5 \\
\hline 9 & 35.30 & 38.20 & 40.00 & OFF & ON & ON & 0.5 \\
\hline 10 & 33.30 & 37.40 & 39.80 & ON & OFF & OFF & 2 \\
\hline \multicolumn{7}{|c|}{ Rata-rata delay hasil ditampilkan di LCD mapun SMS } & 1.05 \\
\hline
\end{tabular}


Pengujian DHT22 pada Tabel 2 menggunakan seterika sebagai simulasi dari kabel trafo yang memiliki suhu mencapai lebih dari $40.00{ }^{0} \mathrm{C}$. Pengujian dilakukan dengan menempatkan sumber panas/setrika bergantian mendekati ketiga sensor. Sensor yang paling dekat dengan sumber panas memiliki nilai yang lebih tinggi yang mengindikasikan bahwa pembacaan sensor lebih baik tergantung dari jarak sensor ke sumber panas. Hasil pembacaan suhu oleh DHT22 dan tampilan nilai suhu yang berada di LCD memiliki delay rata-rata 1.05 detik, sehingga dianggap baik karena jika terjadi perubahan suhu yang cepat, maka dapat segera ditampilkan ke LCD dan diketahui oleh petugas. Hal itu disebabkan oleh adanya delay program serta terdapat faktor dari delay sensor saat membaca suhu. Hasil percobaan berikutnya didapatkan saat sensor mengalami penurunan setelah mencapai suhu tinggi yaitu pembacaan sedikit lebih lama dibandingkan saat pembacaan dengan kenaikan suhu.

\section{Hasil Pengujian SMS}

Tabel 3. Pengujian SMS

\begin{tabular}{|c|c|c|c|c|c|}
\hline \multirow{2}{*}{ No. } & \multicolumn{3}{|c|}{ Alat ukur suhu } & \multirow{2}{*}{$\begin{array}{l}\text { Indikator } \\
\text { SMS }\end{array}$} & \multirow{2}{*}{$\begin{array}{l}\text { Delay pengiriman } \\
\text { sms (detik) }\end{array}$} \\
\hline & $\mathbf{R}\left({ }^{0} \mathrm{C}\right)$ & $\mathbf{S}\left({ }^{0} \mathrm{C}\right)$ & $\mathbf{T}\left({ }^{0} \mathrm{C}\right)$ & & \\
\hline 1. & 25.70 & 28.80 & 34.90 & $\begin{array}{c}\text { Tidak } \\
\text { Terkirim }\end{array}$ & - \\
\hline 2. & 25.70 & 36.80 & 28.80 & $\begin{array}{l}\text { Tidak } \\
\text { Terkirim }\end{array}$ & - \\
\hline 3. & 38.20 & 34.20 & 31.20 & $\begin{array}{l}\text { Tidak } \\
\text { Terkirim }\end{array}$ & - \\
\hline 4. & 33.50 & 36.70 & 40.00 & Terkirim & 4 \\
\hline 5. & 36.50 & 40.20 & 33.10 & Terkirim & 4 \\
\hline 6. & 40.00 & 38.90 & 35.20 & Terkirim & 4 \\
\hline 7. & 33.90 & 37.10 & 39.50 & $\begin{array}{l}\text { Tidak } \\
\text { Terkirim }\end{array}$ & - \\
\hline 8. & 31.00 & 35.60 & 39.30 & $\begin{array}{l}\text { Tidak } \\
\text { Terkirim }\end{array}$ & - \\
\hline 9. & 33.20 & 36.00 & 39.70 & Send & 4 \\
\hline 10. & 35.30 & 38.20 & 40.00 & $\begin{array}{l}\text { Tidak } \\
\text { Terkirim }\end{array}$ & - \\
\hline & $\mathrm{Ra}$ & ata dela & ngirim & & 4 \\
\hline
\end{tabular}

Pengujian SMS dilakukan untuk mengetahui nilai suhu yang dikirimkan ke petugas apakah sesuai dengan hasil pembacaan yang terdapat pada LCD atau tidak dan untuk mengetahui delay pengiriman SMS setelah pembacaan suhu tampil pada LCD. Pengiriman SMS menggunakan modul SIM800L, dimana terdapat kartu GSM yang digunakan untuk mengirimkan pesan dari arduino ke smartphone sesuai perintah pada program arduino. Hasil pembacaan dan delay pengiriman SMS setelah tampilan LCD terdapat pada Tabel 3.
Keakuratan pengiriman SMS dapat dilakukan dengan melihat hasil pada LCD dan pesan teks yang masuk. Kecepatan pengiriman dapat dilakukan dengan menghitung waktu saat suhu tertampil dan ketika pesan masuk ke smartphone.

\section{Hasil Pengujian SMS di Lapangan dengan 2 Alat Ukur}

Pengujian lapangan dilakukan untuk mengkalibrasi alat monitoring suhu dengan alat 
ukur asli yang digunakan oleh PLN GI Jajar Solo yaitu thermogun. Hasilnya ialah alat monitoring suhu memiliki tingkat kesalahan rata-rata $1^{0} \mathrm{C}$, sehingga mempunyai kepresisian yang hampir sama dengan alat ukur thermogun.

Tabel 4. Pengujian Dua Alat Ukur

\begin{tabular}{|c|c|c|c|c|c|c|c|c|c|}
\hline \multirow[b]{2}{*}{ No. } & \multicolumn{3}{|c|}{ Alat ukur suhu } & \multicolumn{3}{|c|}{$\begin{array}{l}\text { Alat ukur } \\
\text { thermogun }\end{array}$} & \multicolumn{3}{|c|}{$\begin{array}{c}\text { Selisih } \\
\text { kesalahan }\end{array}$} \\
\hline & $\begin{array}{c}\mathbf{R} \\
\left({ }^{0} \mathrm{C}\right)\end{array}$ & $\begin{array}{c}\mathbf{S} \\
\left({ }^{0} \mathrm{C}\right)\end{array}$ & $\begin{array}{c}\mathbf{T} \\
\left({ }^{0} \mathrm{C}\right)\end{array}$ & $\begin{array}{c}\mathbf{R} \\
\left({ }^{0} \mathrm{C}\right)\end{array}$ & $\begin{array}{c}\mathbf{S} \\
\left({ }^{\circ} \mathrm{C}\right)\end{array}$ & $\begin{array}{c}\mathbf{T} \\
\left({ }^{0} \mathrm{C}\right)\end{array}$ & $\begin{array}{c}\mathbf{R} \\
\left({ }^{0} \mathrm{C}\right. \\
)\end{array}$ & $\begin{array}{c}\mathrm{S} \\
\left({ }^{0} \mathrm{C}\right. \\
)\end{array}$ & $\begin{array}{c}\mathbf{T} \\
\left({ }^{0} \mathrm{C}\right)\end{array}$ \\
\hline \multirow{2}{*}{1.} & 29.3 & 28.5 & 28.1 & 30.4 & 29.6 & 29.6 & \multirow{2}{*}{1.1} & \multirow{2}{*}{1.1} & \multirow[b]{2}{*}{1.5} \\
\hline & 0 & 0 & 0 & 0 & 0 & 0 & & & \\
\hline \multirow{2}{*}{2.} & 29.8 & 29.1 & 28.1 & 30.7 & 30.0 & 29.9 & \multirow{2}{*}{0.9} & \multirow{2}{*}{0.9} & \multirow{2}{*}{1.8} \\
\hline & 0 & 0 & 0 & 0 & 0 & 0 & & & \\
\hline \multirow{2}{*}{3.} & 30.2 & 29.1 & 30.2 & 31.2 & 30.0 & 30.3 & \multirow{2}{*}{1} & \multirow{2}{*}{0.9} & \multirow{2}{*}{0.1} \\
\hline & 0 & 0 & 0 & 0 & 0 & 0 & & & \\
\hline \multirow{2}{*}{4.} & 31.9 & 29.2 & 30.7 & 30.7 & 30.3 & 31.3 & \multirow{2}{*}{0.5} & \multirow{2}{*}{1.1} & \multirow{2}{*}{0.6} \\
\hline & 0 & 0 & 0 & 0 & 0 & 0 & & & \\
\hline \multirow{2}{*}{5.} & 32.3 & 29.3 & 30.8 & 33.1 & 30.1 & 31.5 & \multirow{2}{*}{0.8} & \multirow{2}{*}{0.8} & \multirow{2}{*}{0.7} \\
\hline & 0 & 0 & 0 & 0 & 0 & 0 & & & \\
\hline
\end{tabular}

\section{Pembahasan}

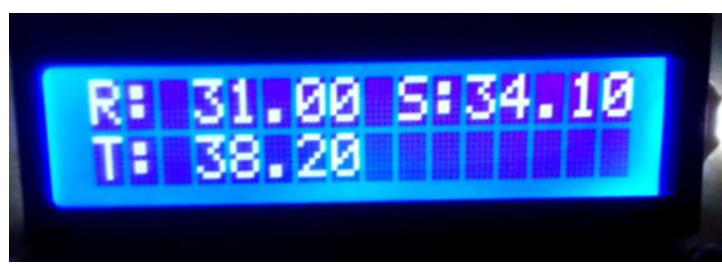

Gambar 7. Hasil pembacaan DHT22

LCD merupakan interface yang digunakan untuk menampilkan hasil pembacaan suhu oleh DHT22 seperti Gambar 7, sedangkan layar pada smartphone sebagai penampil pesan singkat atau SMS yang diterima oleh petugas. Hasil pengukuran didapat dari pembacaan suhu oleh DHT22. Tiap fasa pada kabel trafo memiliki suhu yang berbeda-beda misalnya pada fasa $\mathrm{R}$ ialah $31.00{ }^{\circ} \mathrm{C}$, fasa $\mathrm{S}$ yaitu 34.10 ${ }^{0} \mathrm{C}$, dan fasa $\mathrm{T}$ adalah $38.20{ }^{\circ} \mathrm{C}$, pada keadaan tersebut indikator LED hijau menyala, jika lebih dari $40.00{ }^{0} \mathrm{C}$, maka LED merah dan buzzer menyala.

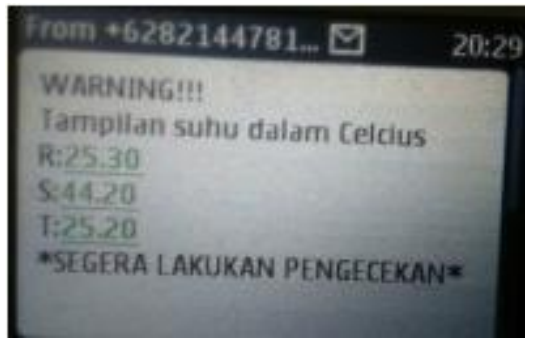

Gambar 8. Hasil Tampilan SMS pada Smartphone

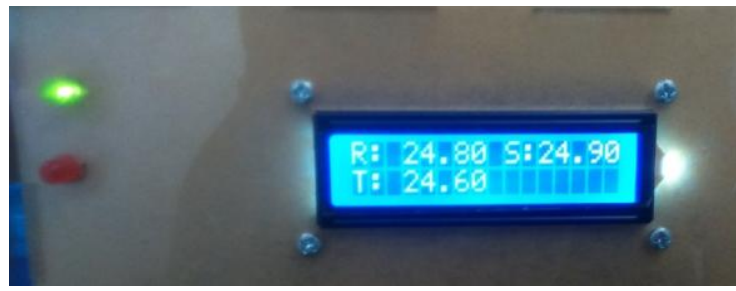

Gambar 9. Tampilan Hardware saat Suhu di Bawah $40.00{ }^{0} \mathrm{C}$

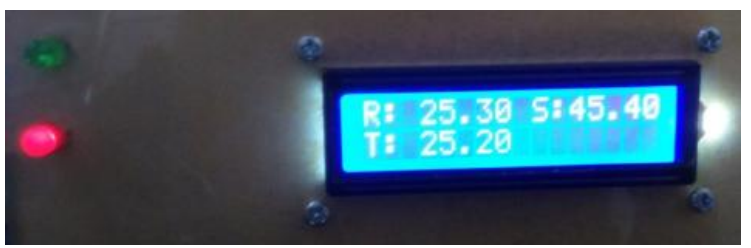

Gambar 10. Tampilan Hardware Suhu di Atas $40.00{ }^{\circ} \mathrm{C}$ 
Data hasil pengukuran akan dikirimkan ke smartphone android terutama saat suhu salah satu fasa melebihi $40.00{ }^{0} \mathrm{C}$ sebagai pemberitahuan pada petugas. Data akan memberikan keterangan nilai suhu ketiga fasa kabel trafo dan peringatan untuk melakukan tindakan. Nilai suhu akan dikirimkan terlebih dahulu untuk ditampilkan ke LCD lalu setelah terbaca ada yang melebih dari $40.00{ }^{\circ} \mathrm{C}$, selang waktu rata-rata 4 detik akan dikirimkan ke smartphone melalui SMS.

Indikator LED bekerja sesuai instruksi yaitu saat LED hijau menyala, maka salah satu suhu dari ketiga fasa di bawah $40.00{ }^{0} \mathrm{C}$. Sedangkan LED merah menyala saat salah satunya di atas $40.00{ }^{\circ} \mathrm{C}$. Proses tersebut juga diiringi pengiriman SMS melalui smartphone.

\section{PENUTUP}

Alat monitoring suhu kabel trafo ini dapat mengukur suhu kabel trafo dengan baik dengan tingkat kesalahan $1{ }^{\circ} \mathrm{C}$. Sensor DHT22 dapat mendeteksi suhu panas mencapai lebih dari $40.00{ }^{0} \mathrm{C}$ sesuai datasheet yaitu batas maksimum pengukuran $80.00{ }^{\circ} \mathrm{C}$. Sistem pengiriman data melalui SMS sudah sesuai perintah dengan kecepatan yang akurat disertai indikator LED maupun buzzer yang menyala pada hardware dekat tampilan LCD. Sensor DHT22 sensitif untuk membaca suhu dengan cepat sesuai jarak antara sumber panas dengan sensor, tetapi memerlukan waktu yang lebih lama saat terjadi penurunan suhu setelah melebihi batas yang ditentukan.

Sebaiknya pada alat ini ditambah 3 sensor DHT22 di bagian clamp agar lebih presisi. Atau sensor DHT22 diganti dengan sensor LASER (Light Amplification by Stimulated Emission of Radiation) agar hasil pengukurannya lebih akurat dan sensor tidak harus mendekati sumber panas. Sumber daya bisa diganti dengan baterai sehingga lebih praktis dan hardware dapat ditempatkan indoor maupun outdoor. Alat ini akan lebih efektif jika digunakan untuk memonitor trafo distribusi di jalan-jalan, sehingga penanganan oleh petugas dapat dilakukan sebelum terjadi kerusakan pada trafo.

\section{DAFTAR PUSTAKA}

[1] Agarwal, P., "Algorithm to Create Multi Line Display from Two Line LCD". 2016 .

[2] DHT22 Writer Team. "DHT22 DataSheet". http://www.datasheetcafe.com/dht22datasheet-pdf/. 2016.

[3] Islam, H. I. dkk "Sistem Kendali Suhu dan Pemantauan Kelembaban Udara Ruangan Berbasis Arduino UNO dengan Menggunakan Sensor DHT22 dan Passive Infrared (PIR)". Prosiding Seminar Nasional Fisika (E-Journal) SNF. 2016.

[4] Kumar, P. "Arduino Based Wireless Intrusion Detection Using IR Sensor and GSM". International Journal of Computer Science and Mobile Computing. 2013.

[5] Kunjumon, S. dkk "Temperature and Humidity Monitoring and Alert Management System". International Journal of Engineering Research and General Science Volume 4. 2016.

[6] Medojevic, M. dkk "Development and Testing of Arduino-based Relative Humidity and Dry Bulb Temperature Data Logger" . XVII International Scientific Conference on Industrial Systems (IS'17). 2017.

[7] Mujawar, T.H. dkk “ Development of Wireless Sensor Network System for LPG Gas Leakage Detection System". International Journal of Scientific \& Engineering Research. 2015.

[8] Pasha, S. “ Thingspeak Based Sensing and Monitoring System for IoT with Matlab Analysis". International Journal of New Technology and Research (IJNTR). 2016. 
[9] Saptadi, A. H. "Measurement Accuracy Comparison between Temperature and Humidity Sensor DHT 11 and DHT 22 Comparative Study at Platform ATMEL AVR and Arduino". 2015.

[10] Shirisha, K. “Acquire Bus Information using GSM Technology". International Journal of Advancements in Technology.
2016.

[11] Zaghloul, M.S. "GSM-GPRS Arduino Shield (GS-001) with SIM 900 Chip Module in Wireless Data Transmission System for Data Acquisition and Control of Power Induction Furnace". International Journal of Scientific \& Engineering Research. 2014 